\title{
The Needs and Priorities for Government Grants for Traditional Korean Medicine: Comparing the Public and Traditional Korean Medicine Doctors
}

\author{
Min Kyung Hyun \\ Department of Preventive Medicine, College of Korean Medicine, Dongguk University, Gyeongju-si, Republic of Korea
}

Correspondence should be addressed to Min Kyung Hyun; mk3three@gmail.com

Received 20 June 2016; Accepted 29 September 2016

Academic Editor: Fabio Firenzuoli

Copyright (C) 2016 Min Kyung Hyun. This is an open access article distributed under the Creative Commons Attribution License, which permits unrestricted use, distribution, and reproduction in any medium, provided the original work is properly cited.

\begin{abstract}
This study was conducted to compare the need for research and development (R\&D) of Traditional Korean Medicine (TKM) perceived by the public and Traditional Korean Medicine doctor (KMD) in. Survey data from 2462 people and KMD were utilized for this study. Overall, $25.10 \%$ of the public and $90.91 \%$ of KMD answered that government grants for TKM R\&D were "extremely necessary." The majority of respondents reported that grants were needed "for the advancement of science and technology in TKM" (public, 46.28\%; KMD, 34.08\%). Research regarding herbal medicine was the top priority of TKM R\&D in both groups. However, "research facilities and training for researchers (27.85\%)" was a close second priority of the public, but not KMD. Moreover, the public believed that safety from adverse effects and toxicity was a more important area of R\&D in each discipline, but KMD did not find these to be important. The public and KMD generally agreed on the need for government grants for TKM R\&D, but the public was more interested in safety than KMD. Therefore, government policy decision makers must consider opinions of both the public and KMD when planning government grants.
\end{abstract}

\section{Introduction}

Currently, many people are interested in traditional medicine (TM) worldwide [1]. In some countries, a high percentage of the population $(20 \%-64 \%)$ use TM $[2,3]$, and $60 \%$ of South Koreans have had experience with Traditional Korean Medicine (TKM) [4]. However, TKM is often unable to maintain its traditional status because it is now required to demonstrate the safety, efficacy, effectiveness, and quality control of TKM products. The demand for scientific evidence related to TM is also increasing as evidence-based medicine is expanding in many countries [5-9]. Accordingly, promoting safe and effective use of TM through research is becoming more important $[1,10]$. In South Korea, many traditional Korean medical doctors (KMD) have long utilized government grants for research and development (R\&D) of TKM, but the R\&D results have not been sufficient to meet the specific needs of the public. This is probably due to the difference in the priority of the public and KMD for TKM R\&D. However, there is no related research about these priorities.
Therefore, this study was conducted to analyze and compare differences in the needs and priorities of the public and KMD using national survey data.

\section{Methods}

2.1. Data. A public survey was conducted to generate a national representative sample. The survey was conducted based on random emails (1880 adults under the age 60) and face-to-face interviews (120 adults over the age of 60) between December 2007 and January 2008 [4]. In addition, a KMD survey was conducted by emailing survey participants among KMD registered in the Association of Korean Medicine between September and October of 2008. After receiving written consent and answered survey questionnaires from $593 \mathrm{KMD}$, survey data from $131 \mathrm{KMD}$ were excluded because they did not work in a clinical setting or did not complete the survey questionnaire (Figure 1).

The survey contents consisted of a demographic part and the need for government grants for TKM R\&D including 


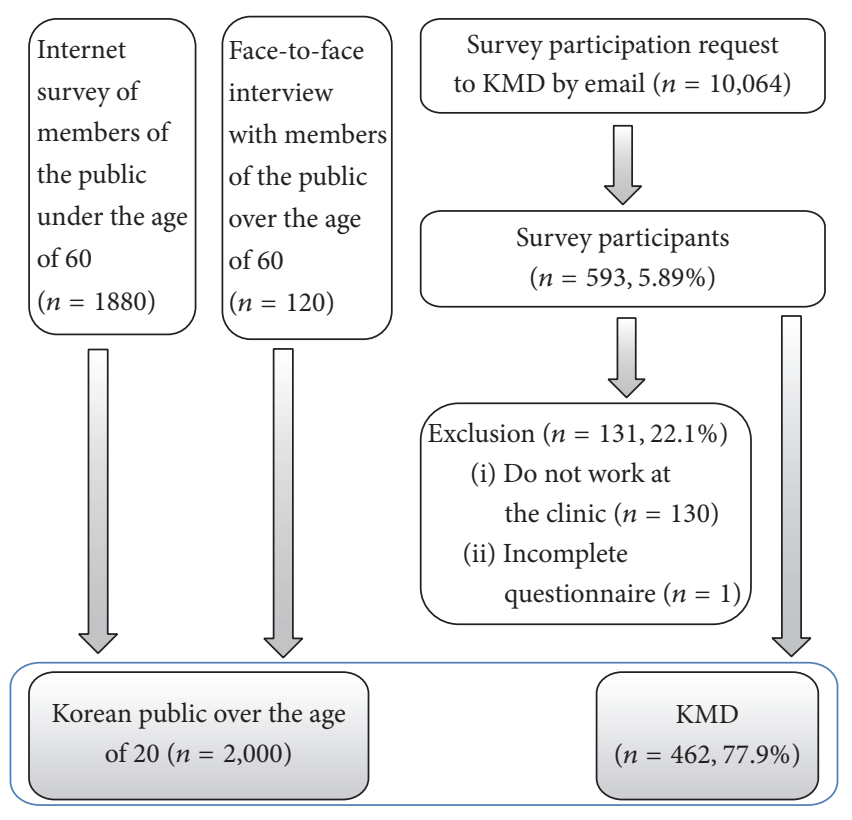

FIGURE 1: Structure of survey data.

needs, reasons, and priorities among the disciplines of TKM $\mathrm{R} \& \mathrm{D}$ and area of each discipline.

This study was approved by the Institutional Review Board of the Dongguk University Gyeongju campus.

2.2. Statistical Analysis. Chi-squared tests were used to compare differences in outcomes between the public and KMD. A two-sided $p$ value of $<0.05$ was considered to indicate statistical significance in this study. Statistical analyses were conducted using Stata/MP version 14 (StataCorp LP, College Station, Texas, USA).

\section{Results}

3.1. Study Population Characteristics. There were differences in all variables including sex, age, annual household income, and education, but regional variations were not significant. Most KMD were male (90\%), aged 30-49 (90\%), with an annual household income of over $\$ 120,000$ (67\%), and all had an education level of university or higher (100\%). Conversely, $50 \%$ of the public were male, $51 \%$ were aged $30-49,70 \%$ had an education level of university or higher, and $78 \%$ had an annual household income of $\$ 12,000$ to $\$ 60,000$ (Table 1).

3.2. The Need for Government Grants for TKM R\&D. There were significant differences between the public and KMD regarding whether research grants were an "extreme necessity," with $25.10 \%$ of the public and $90.91 \%$ of KMD responding to that positively. However, the majority of the public (81.35\%) and KMD (98.7\%) responded that it was a "necessity" or "extreme necessity," while the public (1.75\%) and KMD (0.22\%) responded with "not necessary" or "not necessary at all." Therefore, the public and KMD generally
TABLE 1: Demographic characteristics of the respondents $(n=2,462)$.

\begin{tabular}{lccc}
\hline & $\begin{array}{c}\text { Public } \\
(n=2,000)\end{array}$ & $\begin{array}{c}\text { KMD } \\
(n=462)\end{array}$ & $p$ \\
\hline Sex & & & $<0.0001$ \\
$\quad$ Male & $1000(50 \%)$ & $414(90 \%)$ & \\
Female & $1000(50 \%)$ & $48(10 \%)$ & \\
Age (years) & & & $<0.0001$ \\
20-29 & $425(21 \%)$ & $11(2 \%)$ & \\
$30-39$ & $537(27 \%)$ & $250(54 \%)$ & \\
40-49 & $489(24 \%)$ & $165(36 \%)$ & \\
$50-59$ & $333(17 \%)$ & $31(7 \%)$ & \\
$60-69$ & $216(11 \%)$ & $5(1 \%)$ & \\
Annual household income & & $(n=369)$ & $<0.0001$ \\
$<\$ 12,000$ & $126(6 \%)$ & $7(2 \%)$ & \\
\$12,000-<\$60,000 & $1559(78 \%)$ & $46(12 \%)$ & \\
\$60,000-<\$120,000 & $274(14 \%)$ & $69(19 \%)$ & \\
$\leq \$ 120,000$ & $41(2 \%)$ & $247(67 \%)$ & \\
Education & & & $<0.0001$ \\
High school or less & $606(30 \%)$ & $0(0 \%)$ & \\
University or more & $1,394(70 \%)$ & $462(100 \%)$ & \\
Region & & & \\
Capital & $573(29 \%)$ & $142(31 \%)$ & \\
Metropolitan & $554(28 \%)$ & $108(23 \%)$ & \\
And so forth & $873(44 \%)$ & $212(46 \%)$ & \\
\hline
\end{tabular}

KMD, Traditional Korean Medicine Doctors.

${ }^{*}$ Exchange rate: one US dollar equals 1,000 South Korean Won.

TABLE 2: Perceived need for government grants for TKM R\&D.

\begin{tabular}{lccc}
\hline & $\begin{array}{c}\text { Public } \\
(n=2,000)\end{array}$ & $\begin{array}{c}\text { KMD } \\
(n=462)\end{array}$ & $p$ \\
\hline Extreme necessity & $502(25.10 \%)$ & $420(90.91 \%)$ & \\
Necessity & $1125(56.25 \%)$ & $36(7.79 \%)$ & \\
Somewhat & $338(16.90 \%)$ & $5(1.08 \%)$ & $<0.0001$ \\
Not necessary & $33(1.65 \%)$ & $0(0.00 \%)$ & \\
Not necessary at all & $2(0.10 \%)$ & $1(0.22 \%)$ & \\
\hline
\end{tabular}

TKM, Traditional Korean Medicine; R\&D, research and development.

agreed on the need for government grants in TKM R\&D (Table 2).

3.3. Reasons Why Government Grants Are Needed for TKM $R \& D$. Respondents that felt government grants were a "necessity" or "extreme necessity" were asked to select a reason for this need. The majority of these respondents replied "for the advancement of science and technology in TKM," while the second most common response was "for scientific interpretation of secret recipes" (25.88\%) among public respondents and "for the improvement of TKM's competitiveness in the world market" (23.83\%) among KMD. Among the public and KMD respondents, the third most common response was "to overcome the limitations of western medicine" (Table 3 ). 
TABLE 3: Perceived reasons government grants are needed for TKM R\&D.

\begin{tabular}{lcc}
\hline & $\begin{array}{c}\text { Public } \\
(n=1,627)^{\#}\end{array}$ & $\begin{array}{c}\text { KMD } \\
(n=449)^{\#}\end{array}$ \\
\hline For the advancement of science and technology in TKM & $753(46.28 \%)$ & $153(34.08 \%)$ \\
For scientific interpretation of secret recipes & $421(25.88 \%)$ & $49(10.91 \%)$ \\
To overcome the limitations of western medicine & $239(14.69 \%)$ & $89(19.82 \%)$ \\
To improve TKM's competitiveness in the world market & $107(6.58 \%)$ & $107(23.83 \%)$ \\
To generate evidence regarding TKM effectiveness & $70(4.30 \%)$ & $35(7.80 \%)$ \\
Other & $37(2.27 \%)$ & $16(3.56 \%)$ \\
\hline
\end{tabular}

\# respondents of "extreme necessity" or "necessity" in Table 2.

TABLE 4: Priorities for TKM R\&D.

\begin{tabular}{lcc}
\hline & $\begin{array}{c}\text { Public } \\
(n=2,000)\end{array}$ & $\begin{array}{c}\text { KMD } \\
(n=462)\end{array}$ \\
\hline Herbal medicine & $565(28.25 \%)$ & $218(47.19 \%)$ \\
Research facilities and training for researchers & $557(27.85 \%)$ & $57(12.34 \%)$ \\
Objectification of diagnostic technique & $369(18.45 \%)$ & $106(22.94 \%)$ \\
Acupuncture, moxibustion, cupping & $315(15.75 \%)$ & $46(9.96 \%)$ \\
Medical device for diagnostic/treatment & $188(9.40 \%)$ & $23(4.98 \%)$ \\
Other & $6(0.30 \%)$ & $12(2.60 \%)$ \\
\hline
\end{tabular}

3.4. Priorities for TKM R\&D. Herbal medicine was the first priority in both groups. However, $47.19 \%$ of the KMD placed a priority on herbal medicine $\mathrm{R} \& \mathrm{D}$, while only $28.26 \%$ of the public prioritized this factor. The next greatest priority of the public was research facilities and training for researchers (27.85\%), while for KMD it was "objectification of diagnostic technique." KMD focused on technology itself, while the public prioritized basic investment in R\&D (Table 4).

3.5. Priority Areas of R\&D in Each Discipline TKM. Efficacy of herbal medicine, acupuncture/moxibustion/cupping, and medical devices was the first priority in both groups. Safety from adverse effects and toxicity was the more important research topic for the public but was not a significant factor for KMD. Conversely, development of new diagnostic devices (55.75\% of KMD) and diagnostic assessment tools (53.80\%) was high priorities for KMD, but not for the public (Table 5).

\section{Discussion}

To the best of our knowledge, this study is the first comparison of perception of the needs and priorities of government grants for TKM R\&D of the public and KMD. The results showed significant differences between the public and KMD. Both groups agreed on the need for government grants in TKM R\&D, but 3.6 times more KMD responded that there was "extreme necessity" than the public. Herbal medicine was the top priority of TKM in both groups, but 1.7 times more KMD responded positively to this question than the public.

To date, few studies have investigated research support for TKM [11-13], and we found no discussions based on the opinions of public and traditional medicine doctors about the needs and priorities for TM. An example of government grants for "research facilities and training for researcher" was that the National Center for Complementary and Alternative Medicine (NCCAM) had provided a research training and career development awards for complementary and alternative Medicine (CAM) [11], and the course of evidence-based medicine worked pretty well for CAM researcher [14].

In general, policy decision makers must consider the needs and priorities of both the public and experts before they determine whether to fund various research projects. However, in most cases, experts are brought in to advise government decision makers, while the opinions of the public are excluded. As a result, the priorities of the public, experts, and the government differ. For examples, the Ministry of Health \& Welfare (MOHW) in the Republic of Korea invested about 60 million dollars (exchange rate: one US dollar equals 1,000 South Korean Won) for TKM R\&D from 1999 to 2010 . About $64 \%$ of the total funds were used to support $\mathrm{R} \& \mathrm{D}$ regarding herbal medicine and $15 \%$ was used to support research into TKM medical devices for diagnostic/treatment, while only $9 \%$ was utilized for research facilities and training for researchers. While no differences were found in the first priority of the three groups, the second most common use of MOHW grants was "medical device for diagnostic/treatment"; however, this was a very low priority for the public (9.4\%) and KMD (4.98\%). In other words, there were large gaps between the priority of government grants and priority disciplines between public and KMD groups. Moreover, the difference between the actual support provided by the government and public priority was larger than between that and KMD priority (Table 6). Moreover, 
TABLE 5: Priority areas of R\&D in each discipline of TKM.

\begin{tabular}{|c|c|c|c|}
\hline & $\begin{array}{c}\text { Public } \\
(n=2,000)\end{array}$ & $\begin{array}{c}\text { KMD } \\
(n=461)\end{array}$ & $p$ \\
\hline \multicolumn{4}{|l|}{ Herbal medicine } \\
\hline Efficacy & $760(38.00 \%)$ & $153(33.19 \%)$ & \multirow{6}{*}{0.0176} \\
\hline Safety (adverse effect/toxicity) & $501(25.05 \%)$ & $94(20.39 \%)$ & \\
\hline Quality control/standardization & $330(16.50 \%)$ & $106(22.99 \%)$ & \\
\hline Convenient dosage form & $303(15.15 \%)$ & $90(19.52 \%)$ & \\
\hline Combination therapy of TKM and WM & $104(5.20 \%)$ & $8(1.74 \%)$ & \\
\hline Other & $2(0.10 \%)$ & $10(2.17 \%)$ & \\
\hline \multicolumn{4}{|l|}{ Acupuncture, Moxibustion, and Cupping } \\
\hline Efficacy & $903(45.15 \%)$ & $211(45.77 \%)$ & \multirow{5}{*}{$<0.0001$} \\
\hline Safety (adverse effect/toxicity) & $495(24.75 \%)$ & $40(8.68 \%)$ & \\
\hline Development of new technology & $474(23.70 \%)$ & $159(34.49 \%)$ & \\
\hline Reduction of procedure related pain & $125(6.25 \%)$ & $40(8.68 \%)$ & \\
\hline Other & $3(0.15 \%)$ & $11(2.39 \%)$ & \\
\hline \multicolumn{4}{|l|}{ Medical device for diagnostic/treatment } \\
\hline Efficacy & $842(42.10 \%)$ & $138(29.93 \%)$ & \multirow{5}{*}{$<0.0001$} \\
\hline Safety (adverse effect/toxicity) & $507(25.35 \%)$ & $19(4.12 \%)$ & \\
\hline Development of new diagnostic device & $352(17.60 \%)$ & $257(55.75 \%)$ & \\
\hline Development of new treatment device & $294(14.70 \%)$ & $42(9.11 \%)$ & \\
\hline Other & $5(0.25 \%)$ & $5(1.08 \%)$ & \\
\hline \multicolumn{4}{|l|}{ Research facilities and training for researcher } \\
\hline Researcher training strategy & $935(46.75 \%)$ & $235(50.98 \%)$ & \multirow{6}{*}{0.649} \\
\hline Researcher utilization strategy & $383(19.15 \%)$ & $75(16.27 \%)$ & \\
\hline Electronic medical record for TKM & $363(18.15 \%)$ & $59(12.80 \%)$ & \\
\hline Utilization strategy of research facilities & $169(8.45 \%)$ & $38(8.24 \%)$ & \\
\hline Support strategy of research facilities & $146(7.30 \%)$ & $51(11.06 \%)$ & \\
\hline Other & $4(0.20 \%)$ & $3(0.65 \%)$ & \\
\hline \multicolumn{4}{|l|}{ Objectification of diagnostic technique } \\
\hline Comparative investigation of diagnostic procedures in WM and TKM & $1123(56.15 \%)$ & $144(31.24 \%)$ & \multirow{4}{*}{$<0.0001$} \\
\hline Diagnostic assessment tools & $507(25.35 \%)$ & $248(53.80 \%)$ & \\
\hline Collecting of traditional diagnostic techniques & $368(18.40 \%)$ & $61(13.23 \%)$ & \\
\hline Other & $2(0.10 \%)$ & $8(1.74 \%)$ & \\
\hline
\end{tabular}

WM, western medicine.

TABLE 6: Comparison of priorities for TKM R\&D among MOHW grants, the public, and KMD.

\begin{tabular}{lccc}
\hline & MOHW & Public & KMD \\
\hline Herbal medicine & $1(63.86 \%)$ & $1(28.25 \%)$ & $1(47.19 \%)$ \\
Medical device for diagnostic/treatment & $2(14.83 \%)$ & $5(9.40 \%)$ & $5(4.98 \%)$ \\
Research facilities and training for researcher & $3(8.96 \%)$ & $2(27.85 \%)$ & $3(12.34 \%)$ \\
Acupuncture, moxibustion, cupping & $4(7.79 \%)$ & $4(15.75 \%)$ & $4(9.96 \%)$ \\
Objectification of diagnostic technique & $5(3.74 \%)$ & $3(18.45 \%)$ & $2(22.94 \%)$ \\
Other & $6(0.82 \%)$ & $6(0.30 \%)$ & $6(2.60 \%)$ \\
\hline
\end{tabular}

${ }^{*}$ MOHW grants from 1999 to 2010.

MOHW, Ministry of Health \& Welfare (South Korea).

in most of the total funds invested for efficacy research, there was almost no funding for safety research, including investigation of the adverse effects and toxicity that were considered to be important by the public.
Limitations regarding this study include the following: (a) the KMD survey data may not be fully representative because of the low response rate of $\operatorname{KMD}[15,16]$. However, in the case of KMD, methods other than email survey were 
impossible owing to limitations of the research budget and survey system used by the Association of Korean Medicine [17]. (b) Additionally, the results may not be appropriate for the current situation because the analytical data was collected in 2008. However, this was the best option given the lack of available data. Moreover, this study has great significance for the first comparison of differences in the needs and priorities of the public and KMD using two types of independent nationwide survey data.

Consequentially, government policy decision makers must consider the opinions of both the public and KMD when planning government grants. Safety research should be weighted more heavily than in the past.

\section{Competing Interests}

The author has no conflict of interests to declare with respect to the authorship and/or publication of this article.

\section{Acknowledgments}

This work was supported by the Dongguk University Research Fund of K-2015-G0002-00009.

\section{References}

[1] WHO, WHO Traditional Medicine Strategy: 2014-2023, World Health Organization, 2014.

[2] E. Ernst and A. White, "The BBC survey of complementary medicine use in the UK," Complementary Therapies in Medicine, vol. 8, no. 1, pp. 32-36, 2000.

[3] P. Fisher and A. Ward, "Complementary medicine in Europe," British Medical Journal, vol. 309, no. 6947, pp. 107-111, 1994.

[4] M. K. Hyun, S.-J. Lee, and H. G. Ryu, "Factors associated with utilization and satisfaction of Traditional Korean Medicine in Korea: a national survey," Journal of Society of Preventive Korean Medicine, vol. 19, no. 3, pp. 171-178, 2015.

[5] F. Y. Fung and Y. C. Linn, "Developing traditional Chinese medicine in the era of evidence-based medicine: current evidences and challenges," Evidence-Based Complementary and Alternative Medicine, vol. 2015, Article ID 425037, 9 pages, 2015.

[6] S. K. S. Arabshahi, H. M. Kenari, G. Kordafshari, M. R. S. Ardakani, and S. Bigdeli, "Criteria for evidence-based practice in Iranian traditional medicine," Acta Medica Iranica, vol. 53, no. 7, pp. 419-424, 2015.

[7] I. Masic, M. Miokovic, and B. Muhamedagic, "Evidence based medicine-new approaches and challenges," Acta Informatica Medica, vol. 16, no. 4, pp. 219-225, 2008.

[8] T. Jagtenberg, S. Evans, A. Grant, I. Howden, M. Lewis, and J. Singer, "Evidence-based medicine and naturopathy," Journal of Alternative and Complementary Medicine, vol. 12, no. 3, pp. 323328, 2006.

[9] T. Romeyke and H. Stummer, "Evidence-based complementary and alternative medicine in inpatient care: take a look at Europe," Journal of Evidence-Based Complementary and Alternative Medicine, vol. 20, no. 2, pp. 87-93, 2015.

[10] Y. Kim and S.-H. Cho, "A survey of complementary and alternative medicine practitioner's perceptions of evidencebased medicine," European Journal of Integrative Medicine, vol. 6, no. 2, pp. 211-219, 2014.
[11] P. S. Khalsa and N. J. Pearson, "Financial support for research training and career development in complementary and alternative medicine from the National Institutes of Health," Journal of Manipulative and Physiological Therapeutics, vol. 30, no. 7, pp. 483-490, 2007.

[12] B. Wider and E. Ernst, "CAM research funding in the UK: surveys of medical charities in 1999 and 2002," Complementary Therapies in Medicine, vol. 11, no. 3, pp. 165-167, 2003.

[13] C. N. M. Renckens, "A dutch view of the 'science' of CAM 19862003," Evaluation and the Health Professions, vol. 32, no. 4, pp. 431-450, 2009.

[14] E. S. Allen, E. N. Connelly, C. D. Morris, P. J. Elmer, and H. Zwickey, "A train the trainer model for integrating evidencebased medicine into a complementary and alternative medicine training program," Explore, vol. 7, no. 2, pp. 88-93, 2011.

[15] R. Jones and N. Pitt, "Health surveys in the workplace: comparison of postal, email and World Wide Web methods," Occupational Medicine, vol. 49, no. 8, pp. 556-558, 1999.

[16] A. Scriven and S. Smith-Ferrier, "The application of online surveys for workplace health research," Journal of the Royal Society for the Promotion of Health, vol. 123, no. 2, pp. 95-101, 2003.

[17] M. Ko, J. Lee, K. Yun, S. You, and M. Lee, "Perception of pattern identification in traditional medicine: a survey of Korean medical practitioners," Journal of Traditional Chinese Medicine, vol. 34, no. 3, pp. 369-372, 2014. 


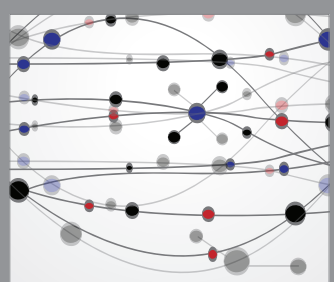

The Scientific World Journal
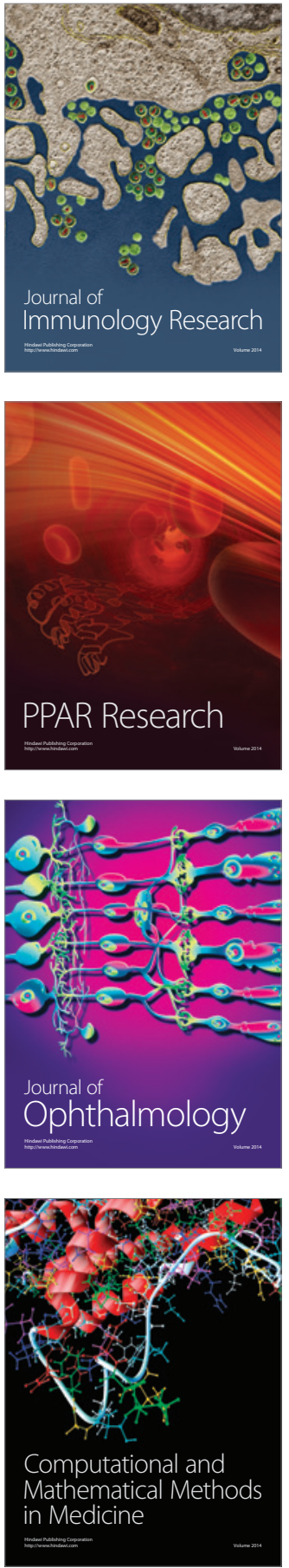

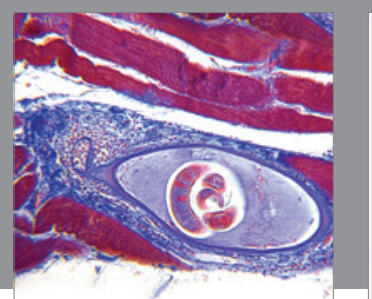

Gastroenterology Research and Practice

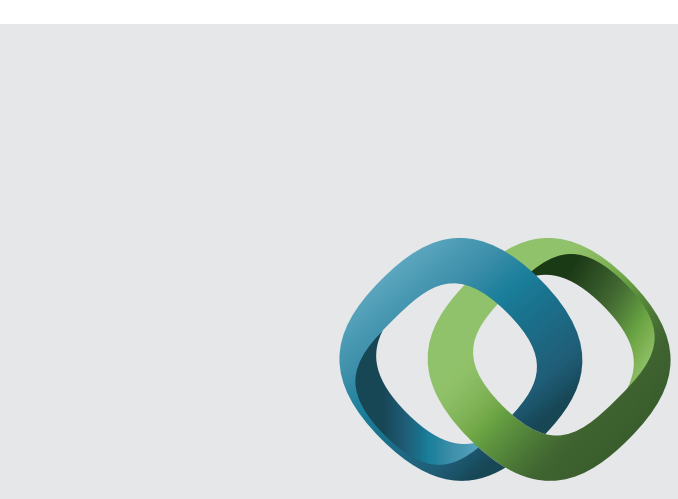

\section{Hindawi}

Submit your manuscripts at

http://www.hindawi.com
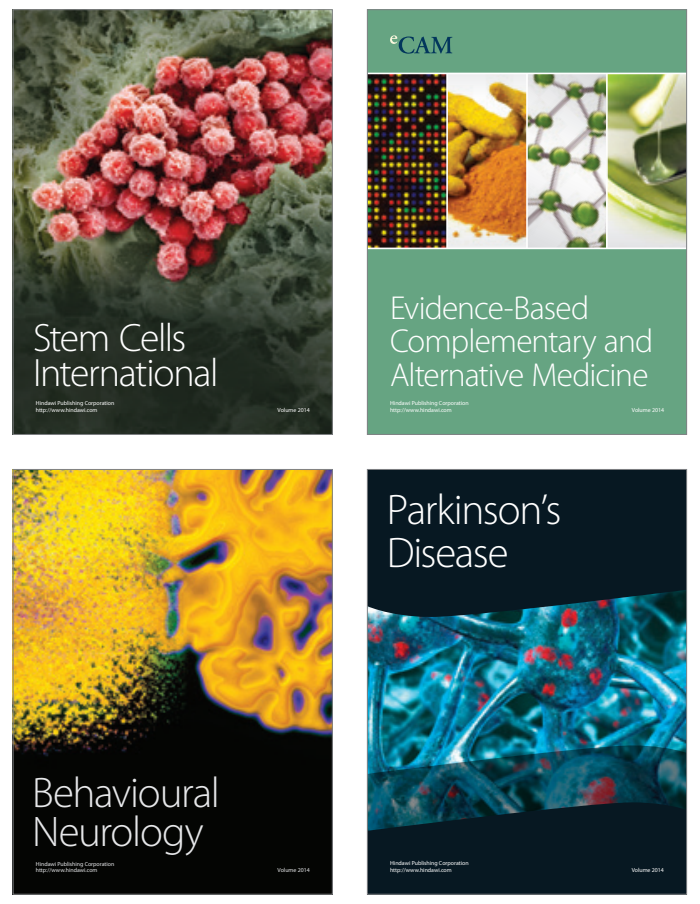
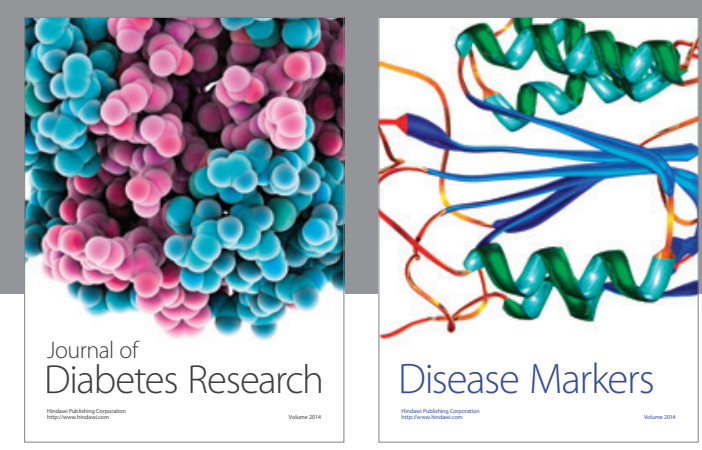

Disease Markers
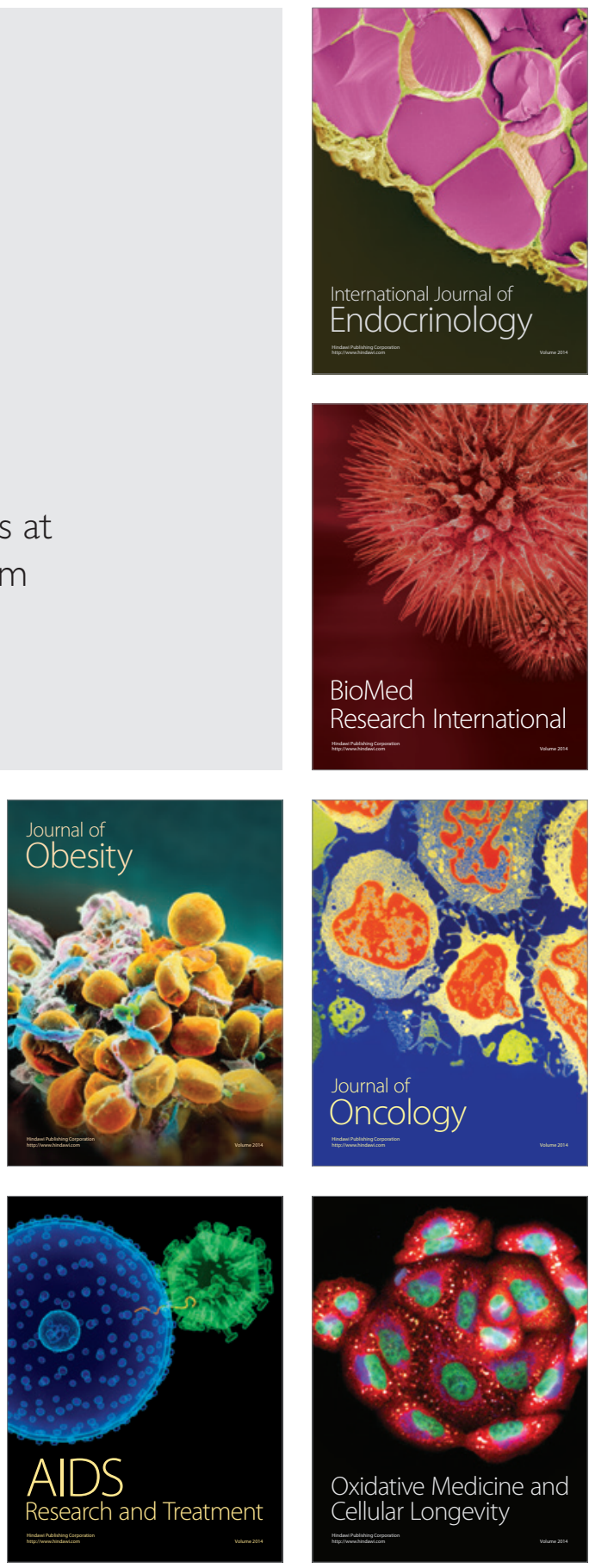